\title{
The lost good self: Why the whistleblower is hated and stigmatized
}

\section{Revised version submitted to Organization Studies}

7 September 2019

\begin{abstract}
In this paper I develop a new explanation that furthers our understanding of why whistleblowers are frequently hated and stigmatized. I call into question the implicit assumption in the literature that whistleblowers are hated and stigmatized exclusively because they represent the 'other'. Instead, I take a different view and argue that, especially where staff have a moral commitment to their work, whistleblowers may also be felt to be problematic because they unconsciously represent the lost good 'self' of staff members. I draw on Kleinian psychoanalytic ideas in developing theory, and use the crisis at the Mid Staffordshire National Health Service Trust in the UK as a contemporary case illustration. This paper contributes to the whistleblower literature as well as to the literature that applies psychoanalytic ideas to the study of management and organization, and it also identifies areas for future research.
\end{abstract}

\section{Key words}

projective identification; psychoanalysis; self; stigmatization; whistleblower 


\section{Introduction}

One of the most striking features of the lives of whistleblowers is that they are frequently hated and scorned by others in their organizations, and are regularly treated with disdain and contempt. Such hatred regularly results in stigmatization so that whistleblowers may 'become targets of harassment, intimidation, investigation, persecution and prosecution' (Ash, 2016, p. 11). In organizations in which whistleblowers have spoken up, it is thus not unusual for a culture to develop in which these whistleblowers are witch-hunted, so that an atmosphere of persecution the 'smell of Salem' (Ash, 2016, p. 49) - pervades. Whistleblowers are thus widely regarded as 'unsettling figures who perturb those witnessing their acts' (Contu, 2014, p. 406), and a key question that follows from this is why this should be the case. Indeed, precisely why whistleblowers are so often intensely hated and stigmatized remains a vital and intriguing issue. For some, the answer may appear obvious: by setting up 'in opposition' to the existing order, whistleblowers constitute a substantial threat and are disliked - or even hated - because they represent the 'other' who would appear to stand up against colleagues and the organization.

In this paper, I take a different view, and suggest that whistleblowers may unconsciously also represent the lost good part of the 'self' of staff members, and that this intensifies the hatred of them, increasing the inclination to stigmatize them. I argue that this lost aspect is felt to be troublesome because it is emblematic of the capacity both to face the truth and do the work of the organization, and, as staff members have lost these functions, it signifies a profound sense in which they and the organization have failed.

I propose that this involves the mechanisms of splitting and projective identification (Klein, 1975), whereby, having unconsciously split the good and bad 
aspects of themselves, staff members project the good aspects into the whistleblower. I argue that these staff members then unconsciously recognise these lost aspects in the whistleblower, a recognition that evokes potentially powerful feelings of shame and guilt in themselves. In order to avoid having these feelings, which are experienced as intolerable, staff members turn to hatred and are inclined to engage in highly irrational, angry and vengeful attacks on the whistleblower and in an attack on the truth. The whistleblower thus becomes the problem, and is subject to stigmatization. I illustrate my argument by exploring whistleblowing during the crisis at the Mid Staffordshire National Health Service (NHS) Trust in the UK, using the Francis Public Inquiry Report (Francis, 2013a; 2013b; 2013c; 2013d) and other secondary data as sources.

The sequence of this paper is as follows. First, I explore the literature by examining some of the central ideas concerning whistleblowers and stigmatization, and, on the basis of this, define the research focus of this paper. Following this I give an account of why the crisis at the Mid Staffordshire NHS Trust was selected as the case material of this study, as well as the methodology and sources used to examine it. After this, drawing on Kleinian psychoanalytic ideas, I outline the theoretical framework of the paper. This is followed by an exploration of the case, with the paper ending with a discussion of the implications of this new understanding, as well as a suggestion of areas for future research.

\section{Literature Review and Research Focus}

There are many, varied definitions of the terms 'whistleblower' and 'whistleblowing' in the literature, and a range of debates around these ideas. While some (such as Near \& Miceli, 1996) argue that only employees may be regarded as whistleblowers, I follow Jubb (1999) and Vinten (1994) who take a wider view and 
define whistleblowing in a broad manner as 'informing on illegal and unethical practices in the workplace' (Vinten, 1994, p. 3). This view includes as whistleblowers not only those who are employees of the organization as well as those who are not, but those who identify themselves when blowing the whistle and those who speak out anonymously, as well as those who lodge their complaints internally as well as those who do it externally.

One area of the whistleblower literature comprises various studies that highlight the ethical dimensions of these activities, with Avakian and Roberts arguing that whistleblowers demonstrate a fundamental 'concern for moral values' (2012, p. 71), Lennane proposing that '[t]he whistleblower acts on principle' $(2012$, p. 249 emphasis in original), and Vandekerckhove and Tsahuridu arguing that the 'duties surrounding whistleblowers resonate with issues surrounding the Good Samaritan' (2010, p. 372). Similarly, Kenny, Fotaki and Vanderkerckhove argue that we best frame whistleblowers' self-construction as 'infused with passionate attachments to organizational and professional norms' (2018, p. 1), Ash proposes that whistleblowing is fundamentally 'an act of loyalty, a commitment to doing right' (2016, p. 16), while Glazer and Glazer regard the whistleblower as a kind of 'ethical resister'.

In a related area of literature, others consider truth to be central to the whistleblowers' concerns, with Weiskopf and Tobias-Miersch (2016) describing whistleblowers' activities as a social practice that disrupts the status quo through the honest speaking of the truth, or 'parrhesia', a kind of truth telling that involves 'frankness, truth, risk, criticism, freedom and duty’ (Weiskopf \& Tobias-Miersch, 2016, p. 1624). Other authors take up the issue of truth in different ways, with Alford arguing that, at the centre of the problem, whistleblowers' 'truths ... [are] ... 
experienced as a threat to power' (2001, p. 3), and Munro (2017) referring to whistleblowing as mobilizing a variety of different kinds of 'truth games'.

A further central area of writing concerns the issues of power and the political dimensions of whistleblowing, with Near, Dworkin and Miceli noting that ' $[\mathrm{t}]$ heories of the whistleblowing process have focused primarily on the political behaviours ... or power processes involved' (1993, p. 394), and Near and Miceli arguing that whistleblowing is in essence 'a political action' $(1985$, p. 9) that involves 'a power struggle among social actors' (1996, p. 521). Especially relevant here, authors such as Mansbach (2007) and Uys (2000) explore the power exercised by institutions and managers in response to whistleblowers, with Parmerlee, Near and Jensen viewing retaliation against the whistleblower as 'one means of control an organization exercises over its members' (1982, p. 20). In a similar vein, Kenny suggests that the silencing of the whistleblower involves 'a matrix of control that not only constrains ... but also produces ... certain kinds of subjects' (2018, p. 1029), while Kenny, Fotaki and Scriver (2018) argue that power circulates between whistleblowers and those who retaliate against them, rather than simply being a resource that is held or not held.

There is also a considerable literature that shows that whistleblowers are often at the receiving end of substantial hatred and stigmatization. While it should be acknowledged that whistleblowers are sometimes viewed in a good light and seen as 'saints' (Contu, 2014, p. 393), they are regularly hated, despised and subject to stigmatization. Sometimes stigmatization is exacerbated by fear, with one whistleblower relating that 'my colleagues won't come near me, they're afraid, like I'm contaminated' (Alford, 2001, p. 75), with such fears being reinforced by 
organizations that use 'disciplinary power ... [that] ... casts the gaze of the entire organization on the whistleblower' (Alford, 2001, p. 104).

The stigmatization literature overlaps with that on retaliation, with some authors using the term 'stigmatization' explicitly, and others using the word 'retaliation', but referring to stigmatizing practices. That said, much of the work in this area owes a debt to Goffman, whose seminal book on stigma 'remains the canonical understanding' (Paetzold, Dipboye \& Elsbach, 2008, p. 186) for these phenomena. The term stigma originates from the ancient Greeks who used signs that 'were cut or burnt into the body ... [in order to signify] ... a blemished person' (Goffman, 1990, p. 11), and Goffman goes on to argue that - albeit in a less 'concrete' way - the cues or markers used by those who stigmatize perform a similar function. As a consequence, someone who is stigmatized is assigned an identity that is 'tainted ... [and] ... discounted' (Goffman, 1990; p. 12), vivid for all to see.

Stigmatization is socially created so that the term 'stigma' is a 'perceptiondriven label held by particular audiences and is not inherent to targets' (Helms, Patterson \& Hudson, 2019, p. 7). Studies of stigmatization include targets that are individuals and groups (Wiesenfeld, Wurthman \& Hambrick, 2008), organizations (Devers, Dewett, Mishina \& Belsito, 2009; Paetzold, Dipboye \& Elsbach, 2008), as well as a literature that covers all of these (Ashforth, 2019; Helms, Patterson \& Hudson, 2019).

The consequences of stigmatization can be highly damaging with Devers et al. concluding that 'a stigma can be extremely harmful and can lead to devastating adverse social and economic outcomes for the stigmatized' (2009, p. 157). Further, Ashforth finds that stigma can provide 'a pretext for discrimination and even abuse' (2019, p. 23), while Wiesenfeld, Wurthmann and Hambrick argue that, as well as 
being highly emotionally painful, stigmatization can involve shunning that 'engenders substantial loss as well' (2008, p. 242).

Within the literature that looks specifically at these practices as they are directed towards whistleblowers, Rehg, Miceli, Near and Van Scotter (2008) understand retaliation as an 'undesirable action taken against a whistleblower ... who reported wrongdoing' (2008, p. 222). Jubb (1999) argues that, at core, whistleblowers are treated badly because they are experienced as having acted in disloyal and dissenting ways, Ash finds that they are often 'vilified, typecast as a rat, snitch or 'difficult'; as mentally ill, malicious or vengeful' (2016, p. 16), while Perry argues that the consequences of whistleblowing make it a form of 'occupational suicide' (1998, p. 235).

Some of this retaliation may be understood as involving stigmatization because, as already suggested, cues or markers - usually vivid to the whistleblower and colleagues alike - may be used to identify the whistleblower. A wide variety of such cues may be used, ranging from 'concrete' and highly visible actions that involve the damaging of property, such as the cutting into pieces of the mail of New York Police Department whistleblower Sergeant Joseph Trimboli (James, 1993). Alternatively, they may be much less 'tactile' or 'concrete' and involve spoken or written words that label the whistleblower, such as the verbal and especially written assaults on HBOS whistleblower Paul Moore that described him as outrageous, a description that felt to him to involve a 'death blow' (Moore \& Haworth, 2015, p. $362)$.

In summary, my view is shaped by the literature that suggests that whistleblowers are involved in ethical activities that concern speaking the truth, are regularly on the receiving end of hatred, retaliation and stigmatization, and often 
experience damage to their emotional lives, livelihoods and career prospects. However, noting that writers in this field invariably view those who are hated and stigmatized as people who are 'other' or different from those doing the stigmatizing, I take an alternative view of this matter.

This view of the whistleblower as 'other', widespread in the literature, is present for example in the work of Rothschild and Miethe who state that whistleblowers face both management retaliation (1999) and 'ostracism by coworkers' (1999, p. 120), as well as Kenny, Fotaki and Scriver who argue that 'employers and co-workers can resort to reprisals' (2018, p. 2) against whistleblowers. Similarly, Mesmer-Magnus and Viswesvaran point out that 'top management ... supervisor or coworkers' (2005, p. 281) may initiate actions against the whistleblower, while Rehg, Miceli, Near and Van Scotter (2008) argue that retaliation against whistleblowers is indicative of a conflict between the organization and its employees. Further, whistleblowers are seen as 'other' than the rest of the peer group and are 'likely to be accused of disloyalty to peers' (Jubb, 1999, p. 82) and therefore censored, cast out and treated as 'derealized subjects' (Kenny, 2018, p. 7). In sum, whistleblowers invariably are seen to be different and 'other' than the rest of the peer group, management and the organization.

While acknowledging the important and decisive contributions of many of these authors, I depart from their view by proposing the novel idea that whistleblowers may represent not only the 'other' but also, unconsciously, the lost good part of the 'self' of the staff member projected into the other, and that this helps to explain the deep hatred felt towards them, as well as the resulting stigmatization. My view also recasts well-established views about the significance of power because it suggests that a power struggle exists not only 'externally' between staff members 
and whistleblowers, but also 'internally' within the minds of staff members, who, at an unconscious level, are effectively at war with themselves.

\section{Choice of Case}

In this paper I use the 2005-2008 crisis at the Mid Staffordshire National Health Service (NHS) Trust in the UK as a case illustration of the stigmatization of whistleblowers. One reason for this choice is the magnitude of the disaster that occurred: according to The Guardian, the crisis at Mid Staffordshire was 'the biggest scandal of NHS care in years .... [one that] ... has become a byword for ... dangerously inadequate treatment' (Campbell, 2011). As Ash puts it, Mid Staffordshire manifested a "caricature of "care'" $(2016$, p. 15) that provides 'a masterclass in what and how disasters occur' (2016, p. 109). In the context of the urgent need for a fuller exploration of professional misconduct in healthcare (Currie, Richmond, Faulconbridge, Gabbioneta \& Muzio, 2019), this was thus a crisis of considerable significance, and this made it an appropriate choice for this paper.

A second reason for choosing this case has to do with the credibility of the key whistleblowers at Mid Staffordshire. Research shows that 'personality characteristics ... are not consistently related to whistle-blowing' (Near \& Miceli, 1996, p. 511), and the question is invariably raised as to whether purported whistleblowers are flawed characters, 'crackpots' (Near \& Miceli, 1996, p. 510), motivated by 'sour grapes' (Mesmer-Magnus \& Viswesvaran, 2005, p. 277), 'squealers' (Mesmer-Magnus \& Viswesvaran, 2005, p. 277), or those who are inclined to act the ' gadfly' who threatens to file complaints when no reasonable basis exists' (Miceli \& Near, 1994, p. $65)$.

At Mid Staffordshire, however, these issues need not concern us. Indeed, the evidence suggests that the Mid Staffordshire whistleblowers - and especially the two 
key people involved, Helene Donnelly and Julie Bailey - acted properly and appropriately and in circumstances in which it was entirely correct to file complaints. Indeed, the award of an Order of the British Empire (OBE) to Donnelly and Commander of the British Empire (CBE) to Bailey provides further, strong evidence that this is the case. For these reasons - the significance of the case and the credibility of the whistleblowers - the Mid Staffordshire case was selected for exploration in this paper.

\section{Methodology and Sources}

This study is broadly located in the tradition of that employs text-based research to explore particular cases (Brown, 2004; Brown \& Jones, 2000). One subset of works within this tradition uses the lens of psychoanalysis to understand such cases (Kenny, 2012; Stein, 2016). Psychoanalysis is useful because, by offering a well-developed set of ideas that help us expand 'psycho-social inquiry to the study of affect and emotion' (Fotaki, Long \& Schwartz, 2012, p. 1109), it 'increases the explanatory power of organization and management studies' (Arnaud, 2012, p. 1122).

A qualitative (rather than quantitative) analysis of these texts was undertaken because, as Brown argues, '[o]nly a qualitative approach permits the highlighting of nuances of meaning' $(2004$, p. 98). This 'qualitative approach is also consistent with research that draws on psychoanalytic ideas' (Stein, 2016, p. 924). Central to the approach adopted in this paper is the creation and development of psychoanalytically informed 'working hypotheses', one that has been used in studies based on primary (Miller, 1993) as well as those based on secondary data (Stein, 2016).

These working hypotheses were subject to several rounds of scrutiny and examination, with some being modified, re-formulated or discarded (Cresswell, 1994). Such a method of hypothesis formulation is an iterative process that involves 
going back and forth between theory and data, discussing and presenting ideas to others, and creating and re-working hypotheses. A total of six conference presentations of different versions of the paper were made to colleagues from the disciplines of organization studies, psychoanalysis and group relations, and a number of separate discussions were held with particular colleagues from these disciplines. By way of illustration, in exploring the research question of why whistleblowers are often so hated and stigmatized, a number of early and provisional working hypotheses were formulated. Some of these initial hypotheses were shaped by Kleinian psychoanalytic ideas - the theoretical framework employed in this paper - that propose that evidence of deeply entrenched hatred points to two supplementary ideas for exploration. One such idea is that the hatred may emerge from potentially painful experiences that are being avoided, or, to use the technical term, defended against (Braddock, 2011, p. 645). At this initial stage of the exploration, that which was being avoided or defended against was unknown, and required further thought and examination. Following further exploration, it was hypothesized that the experience that was felt to be excessively painful that was being defended against was the staff member's collusion with the neglect, misdemeanours and corruption that were brought to their attention by the whistleblower.

A second idea is that the hatred may involve projective identification (Klein, 1975), that is the unconscious export of parts of the self of the staff member into the whistleblower, as the means of defending against and avoiding the unwanted experiences described above. A key moment of inspiration in relation to the present paper occurred when I read the account of the projection of the bad self in the excellent book chapter by Waddell (1998), with this reading constituting perhaps the 'point of origin' of my paper. As her idea of the projection of the bad self also 
reflected the extant writings on projective identification in the organization studies literature (Gilmore \& Krantz, 1985; Petriglieri \& Stein, 2012; Vince \& Mazen, 2014), this seemed to provide a good start for thinking about what happens to whistleblowers.

A hypothesis was thus formulated that staff members had projected their own, bad, unwanted selves into the whistleblower, so that the whistleblower would be felt to be problematic, while the staff members themselves would be absolved of the responsibility to examine their own collusion. The idea of the projection of the 'bad' parts of the self seemed at first sight to have plausibility because of the degree of hatred and aggression exhibited towards these whistleblowers: if staff members hated whistleblowers so intensely, perhaps it was because their own bad selves had been projected into - and were therefore being unconsciously 'carried' by - such whistleblowers.

However, during conference presentations and discussions of early drafts of the paper it became clear that this early projective identification hypothesis fell short because it did not account for the ethical nature of the actions of whistleblowers, for the likelihood that, at some level, they represented honesty and truth-telling. The working hypothesis about the projection of the bad self was thus subsequently discarded and - following Klein's (1975) view that projective identification follows the splitting into mutually exclusive good and bad aspects of the self - a new hypothesis was formulated suggesting that it was the good (rather than bad) self that was projected and held by the whistleblower.

However, once again there were challenges because - as emerged during later conference presentations and discussions - it became obvious that a conceptual problem had been opened up by this new formulation as it was not clear, at this stage 
of the analysis, why the projection of the good self should result in such hatred: while it makes sense that those who project their bad selves into others are likely to hate those others because they unconsciously recognise in them detested parts of themselves (Petriglieri \& Stein, 2012; Vince \& Mazen, 2014), it was not immediately clear how the projection of the good part of the self would result in similar kinds of hatred. Following further consideration and discussion, the hypothesis was subsequently modified and developed along the lines that the unconscious recognition of the good self in the whistleblower evoked enormous unconscious shame and guilt in the staff members because it unconsciously reminded them of what they had lost, and that, rather than experience such emotions, staff members turned to hate the whistleblower as a way of expelling such feelings. Finally, following further conference presentations and discussions, the views expressed in this paper were settled on.

The text-basis of this research was facilitated by the wealth of data on the fiasco at Mid Staffordshire made available by the Francis Public Inquiry Report (Francis, 2013a; 2013b; 2013c; 2013d) into the crisis, as mentioned earlier. Public inquiry reports 'have attracted considerable attention from scholars' (Brown, 2004, p. 98) and have constituted major sources in facilitating the understanding of specific cases in organization studies (Brown, 2004; Brown \& Jones, 2000; Gephart, 1993), and this paper follows this tradition. Authored by QC Robert Francis, the Report of the Mid Staffordshire Public Inquiry provides extensive and detailed accounts of what happened in this case. During the inquiry, 352 witness statements were taken, with a wide range of healthcare professionals, officials, politicians and others involved in commissioning, performance management, oversight and regulation in the health care system also being consulted. Running to three volumes and a total of 1783 pages, as 
well as an Executive Summary of a further 125 pages, the Report constitutes a notable and important document, and, together with other secondary sources, this therefore provided a substantial amount of data for the basis of this paper.

While considerable scholarship and care went into this study, it needs to be acknowledged that other plausible accounts of these events have been developed, and that, while opening up certain possibilities, the Kleinian psychoanalytic approach offered here inevitably excludes others. I thus acknowledge that this study is undertaken 'within a particular scholarly discourse' (Brown \& Jones, 2000, p. 659), and that it privileges certain voices rather than others (Pentland, 1999). In spite of these limitations, it is hoped that this paper advances knowledge and helps us understand these complex phenomena in a new and interesting way.

\section{The Whistleblower and Projective Identification}

I now turn, using Kleinian psychoanalytic ideas, to develop theory around the issues of the hatred and stigmatization of whistleblowers. As has been noted, those who blow the whistle in relation to wrongdoing regularly find that others in the organization bear feelings of hatred towards them, and are inclined to stigmatize them. One way to frame these tensions is to consider what is signified by these whistleblowers and their actions. If, as Ash argues, whistleblowing is 'an act of loyalty, a commitment to doing right' (2016, p. 16), I would argue that the whistleblower unconsciously signifies a crucial and important ethical part of the selves of organizational members, albeit one that they have lost, and is no longer available to them. After all, it is not the organizational member but the whistleblower who has faced the truth by alerting people to problems and wrongdoing, stood out from the crowd and risked being seen as an enemy, all of which requires considerable courage. I would argue therefore that there is an unconscious recognition in the minds 
of staff members that the whistleblower is giving voice to the ethical aspects of themselves, and that this triggers an unconscious recognition that the good and ethical aspects of the self of the organizational member have been lost, and are now lodged in the whistleblower.

Understood in this way, whistleblowers may unconsciously (a), on behalf of the organization, represent the functions of honesty, integrity and candidness, of asking why things happen as they do, of knowing and facing the whole truth, and thus represent these functions of organizational members that they have lost, and cannot retrieve. Added to this, (b) the whistleblower may unconsciously be felt to have taken on the function and the actual work of the staff, of focusing on the task of the organization, thus deepening the problem. In a health service, for example, the whistleblower may be felt unconsciously to represent the functions of taking care of patients, diminishing the risk of illness and saving lives, functions intrinsic to any health service operation.

These phenomena may best be understood as involving, first, splitting (Klein, 1975; Fotaki, 2006; Fotaki \& Hyde, 2015; Baker \& Kelan, 2019), the primitive mechanism that facilitates one to radically split good from bad, resulting in them appearing entirely separate and exaggerated; and, second, projective identification (Gilmore \& Krantz, 1985; Horwitz, 1985; Klein, 1975; Petriglieri \& Stein, 2012; Vince \& Mazen, 2014) whereby certain of these aspects are unconsciously projected into others. Splitting and projective identification are engaged in by individuals in order 'to protect themselves from consciously experiencing unbearable feelings' (Petriglieri \& Stein, 2012, p. 1222), and thus function as mechanisms of defence (Braddock, 2011, p. 645; Vince \& Mazen, 2014, p. 191) because they are employed for the purposes of protecting the self from such painful and difficult feelings. They 
are unconscious processes in that those using them have little or no conscious awareness of the difficult feelings they are trying to avoid, nor how they employ these mechanisms in order to enable them not to have such feelings. These processes are also largely involuntary, being used in ways that are reactive and not thought out.

Such splitting and projective identification is however highly irrational because the protection it offers comes at high cost insofar as (a) it precludes awareness and examination of the difficult issues associated with the feelings that are being avoided, and (b) may also initiate complex, problematic and potentially damaging interactions with those who are projected into. Although it is possible to engage in splitting and projective identification with recipients who are unaffected by these processes, recipients may well be deeply affected because they feel themselves to be on the receiving end of such unpleasant and difficult projections; this is known as the 'evocatory' (Spillius, 2012, p. 58) aspect of projective identification.

It is important to note that, while building on Freud's idea of projection as the attribution of one's own feelings to another, Klein's projective identification is a broader concept that includes the idea that parts or functions of the self are unconsciously split off and lodged in the other (Mason, 2012, p. 303). Thus, as indicated above, if one engaged in projective identification one may be left with unconscious feelings that the other possesses one's own functions or capacities, such as the capacity to care, think, or do effective work. While the idea of projective identification involving the lodging of the bad parts of the self in others has already been explored in the organization studies literature (Gilmore \& Krantz, 1985; Horwitz, 1985; Petriglieri \& Stein, 2012; Stein, 1998; Vince \& Mazen, 2014), the idea of the projection of the good parts of the self, examined in this paper, has up until now not been examined in this area of study. 


\section{Consequences of Projective Identification}

As staff members have unconsciously located their good selves in the whistleblower, there is a deeply problematic sense in which the whistleblower may unconsciously remind staff of all that is associated with the good aspects of themselves, of their very purpose or function, their reasons to be in the organization, and of the ethical imperatives of their job, all of which they have lost. This reminding of staff members of what they have lost is highly charged because it alludes to a sense of failure, that they have lost touch with the truth of the deficiencies of the organization, and that they themselves have failed, or at least colluded with the shortcomings or misdemeanours of others.

Unconsciously representing the good self that has been lost, whistleblowers are thus likely to become an enormous problem for these staff members because they force staff members to glimpse disaster (Bion, 1967, p. 86), as well as staff members' own role in creating such a disaster. Indeed, the actions and statements of the whistleblower are felt to be highly persecutory and imbued with accusation concerning the catastrophe that has been produced through inaction, collusion and/or dishonesty.

Glimpsing disaster may be felt to be so disturbing and problematic that it leads to deep feelings of hatred towards the person who has identified the catastrophe, had the impudence to speak up, and alerted others to it: having had sight of the disaster that has been identified, such concerns thus get transformed into animosity, hatefulness and spite so that there are 'outbreaks of ... hatred' (Bion, 1967, p. 89) towards the person who has spoken the truth, in this case the whistleblower. Such hatred involves the mobilization of Thanatos or the 'death instinct', a force that is 'mute and hidden' (Rosenfeld, 1987, p. 107) so that those in whom it is manifest have 
little or no conscious awareness of how it infects them and what damage it causes. When fuelled by Thanatos in this way, projective identification therefore becomes a highly irrational process that makes matters considerably worse, because these issues cannot be owned and addressed, and are instead located in the whistleblower.

These staff members thus lay the blame - and locate the problem - at the door of the whistleblower, effectively blaming the messenger, precisely because the whistleblower's offence has been to bring the good self into focus, and make vivid that staff members have failed and no longer have access to this aspect of themselves. As Fotaki and Hyde put it, 'blame involves projecting ... parts ... [of the self] ... onto other people ... because an external conflict is preferable to the consequences of having to engage in self-examination' $(2015, \mathrm{p} .446)$. The other, in this case the whistleblower, as Waddell puts it, thus 'becomes the repository for feelings which cannot be acknowledged as part of the self' (1998, p. 127), and is thus scapegoated and 'blamed or punished for the sins of others' (Waddell, 1998, p. 127).

To borrow again from Bion, for the one doing the blaming the only misfortune would seem to be the existence of the person who has spoken the truth $(1967$, p. 88), someone who is experienced as an 'obstructing force' (1967, p. 90), in this case the whistleblower. The lost good self that the whistleblower represents thus necessarily gets transformed into something evil and malign, and much energy needs therefore to be expended to destroy this person and their ideas, or, if this is not possible, to mark them out as tainted and damaged, so that all, whistleblower and staff member alike, can see. As Waddell writes in relation to those who are scapegoated, '[t]he group feels persecuted by their collective wrong-doing' (Waddell, 1998, p. 128), and this is 'addressed' by locating the problem with the scapegoat, and this is especially true in the case of the whistleblower. 
Such scapegoating may be acted out and may involve attacks that lead to serious consequences for whistleblower. Where whistleblowers are employees of the organization, they may be fired, but, principally because of the fear that they would be more effective in their criticism of the organization once outside it, they are often kept within the organization. Whistleblowers are thus usually 'not fired outright' (Alford, 2001, p. 31), with the 'usual practice ... [being] ... to demoralize and humiliate the whistleblower' (Alford, 2001, p. 31-32) within the organization, where they are excluded and stigmatized. Stigmatization is thus regularly the practical manifestation of this hatred, and various means are employed to enact it, such as using oral communication, written communication, signs, gestures or territorial isolation to mark whistleblowers out as different. Whichever means are used, the key issue is that the whistleblower is stigmatized and tainted for all to see.

\section{Crisis at Mid Staffordshire}

I now turn to illustrate these themes by examining the experience of whistleblowers during the crisis at the Mid Staffordshire NHS Trust, a crisis that, as has already been noted, was one of the most serious in the UK health service in recent times. According to the Francis Inquiry, 'conditions of appalling care were able to flourish' (Francis, 2013d, p. 7) between 2005 and 2008 at Mid Staffordshire, and especially at its main hospital in Stafford, conditions that included large numbers of patients suffering unnecessary and premature deaths; patients being left in excrement and soiled bed clothes for lengthy periods; assistance not being provided to patients who were unable to feed themselves; water being unavailable to patients; ward and toilet facilities being in a filthy condition; and death certificates regularly being inaccurate or incomplete. Further, as described below, in order to keep up 
appearances and meet targets, in pursuance of the 'Foundation Status' that the Trust so eagerly sought, records were falsified.

The culture at the Trust, as is evident from the Francis report, was characterised by widespread denial about the nature and scale of the problems. As Trust Chief Executive Antony Sumara subsequently acknowledged, there was a 'culture of denial that permeated to all levels of ... [Stafford] hospital' (Francis, 2013a, p. 170), and it is clear that this was largely the case throughout much of the Trust. Such denial was especially evident within the Trust's leadership, with the Inquiry concluding that Trust Chair Toni Brisby 'had no grasp of the enormity of what has been uncovered at Stafford under her watch' (Francis, 2013a, p. 160).

As well as there being a strong culture of denial about the extent of the difficulties, when problems were uncovered, there was a powerful inclination to blame individuals for them, threaten their jobs, and coerce them to cover these problems up. Clinical Lead for Emergency Medicine Dr Chris Turner, for example, found that - when he arrived at the Trust - the Emergency Department was an 'absolute disaster... [in which] ... staff, both medical and nursing, were utterly demoralized ... [with a] ... blame led culture ... [that manifested in] ...bullying and harassment towards staff' (Francis, 2013a, p. 121). Specifically, not only were nurses blamed for the problems created by others, but they were blamed if they were not prepared to engage in a cover-up of these problems, so that they were were 'threatened on a near daily basis with losing their jobs ... [and] ... it was quite normal for nurses to come out at the end of ... meetings crying' (Francis, 2013a, p. 121). The blame led and victimizing culture was similar for doctors, with Ash observing that doctors in the Trust had no option but to 'kept quiet, because to raise ... [concerns] ... would be ... career suicide' (2016, p.109). 


\section{The Emergence of Whistleblowers at Mid Staffordshire}

In spite of the obvious risks to themselves, various people emerged as whistleblowers in response to the crisis. One was Terence Deighton, a retired government adviser and member of Stafford Hospital's Patient and Public Involvement in Health Forum, who wrote a letter of complaint to a local newspaper following an inspection he undertook concerning hygiene standards (Sawer, 2009). Not only were the hospital authorities insistent that his account was implausible, but the Trust's Chief Executive threatened to have him removed from hospital premises 'on grounds of trespass' (Sawer, 2009), should he ever attempt a further unannounced inspection.

A number of employees at the Trust also raised their heads above the parapet in complaint. A significant group were consultant doctors, and in particular, Dr Peter Daggett and Dr Pradip Singh. Managers and authorities at the Trust were quite unsympathetic to the concerns of these doctors, with Dr Daggett reporting that, together with other consultants who complained, he was seen as one of the "naughty boys' (Francis, 2013a, p. 238) at the Trust, and Dr Singh being suspended following his complaint, and only being reinstated (with apology) after the arrival of a new Medical Director (Francis, 2013a, p. 240).

Most notable among the employees who complained, however, was Helene Donnelly, a nurse who worked in the Accident and Emergency Department. Donnelly was especially unhappy about inadequately trained and inexperienced staff being required to deal with a level of work that left them 'terrified' (Francis, 2013c, p. 1502), low staffing levels, as well as faulty equipment and a range of other issues. Particularly upsetting for Donnelly was that she had 'seen people die, needlessly' (Francis, 2013a, p. 237) on a relatively frequent basis. 
The problems for Donnelly were exacerbated by the expectation that Accident and Emergency nurses should 'fabricate patient nursing notes' (Ash, 2016, p. 35) and effectively be 'asked to lie' (Ash, 2016, p. 36) in order to hide breaches in waiting times so that a four-hour waiting time limit for patients would appear to be met. Indeed, the two Sisters in charge of Donnelly's ward instructed their staff to falsify and substantially understate waiting times in official reports, speaking nastily and swearing at nurses who did not change the times, or changing the times themselves (National Health Executive, 2013), and justifying this by telling them that, if targets were not met, 'heads would roll' (National Health Executive, 2013). Having raised her concerns with the Sister, Staff Nurse and Clinical Service Manager, Nurse Donnelly overheard the Sister tell the Staff Nurse to instruct her to lie (Francis, 2013c, p. 1503). As a result, Donnelly would regularly go home in tears. However, she continued to make representations about her concerns, making nearly one hundred over the duration of her time at the Trust.

There were also whistleblowers who were not employees of the Trust, the most prominent of whom was Julie Bailey, a woman who began a highly public campaign after the death of her elderly mother while a patient in Stafford hospital. Following her mother's admission to the hospital, Bailey quickly became aware of the deficiencies of the service, with a 'culture of neglect' in which there was a 'complete disregard for a patient's well-being' (Francis, 2013a, p. 537) on her mother's ward. According to Bailey, at the point that her mother was ready to be discharged, the nursing staff 'dropped her trying to put her back in bed ... [so that] she landed on her back' (Adams, 2013). The following day her mother was struggling to breathe, but it took the hospital three days to get a doctor to see her. When, finally, Bailey was able to speak to a doctor about her mother's condition, she reports that he was highly 
unsympathetic and said 'your mother is going to die a painful death and she will go just like that' (Adams, 2013), clicking his fingers as he spoke.

Bailey was deeply angry and distressed about the doctor's comments, and her mistrust of the staff ratcheted up. As a result of this mistrust, in rotation with her daughter and niece, she moved into the ward full time, determined to look after her mother (Adams, 2013). Bailey was thus able to feed and look after her mother during the last weeks of her life, as well as others on the ward who were unable to care for themselves (Francis, 2013a, p. 537).

Following her mother's death, and using the café she ran in Stafford town as her headquarters, Bailey started a campaign that became known as 'Cure The NHS', one which became a 'lightning rod' (Adams, 2013) for complaints about the health service throughout the UK. Bailey and her supporters plastered the walls of her café with photographs of elderly men and women who had died unnecessarily at Mid Staffordshire, and this 'impromptu shrine acted as a focus for the campaign, a constant reminder of the scandalous conditions being endured by hundreds of patients' (Sawer, 2009) at the Trust.

Bailey also wrote a series of lengthy letters of complaint to various people in the Trust and the Borough Council. Detailing the 'appalling story' (Francis, 2013a, p. 536) of her mother's fate at the hospital, one of these letters was experienced as a 'real bombshell' (Francis, 2013a, p. 538) by those on the Trust's staff. That said, the response of the authorities to her letters was invariably disappointing (see, for example, Francis, 2013a, p. 537).

\section{The turn to Hatred and Stigmatization at Mid Staffordshire}

The whistleblowers at Mid Staffordshire, and especially Helene Donnelly and Julie Bailey, provoked angry reactions and stigmatization from other staff that 
included explicit or implicit threats to their lives. Senior nurses' responses to Helene Donnelly's concerns were, as she puts it, 'extremely aggressive... [and involved] ... accusing me and anyone else who agreed with me of not being team players' (Francis, 2013a, p. 108).

Further, the atmosphere of intimidation intensified over time, with Donnelly reporting that 'threats were made, both directly and indirectly ... [with colleagues] ... very often coming up to me ... [saying I should] ... "watch my back" ... [and] ... “you shouldn't have spoken out"” (Francis, 2013a, p. 236). Donnelly was told by other staff that they knew where she lived, and that she should be careful for her safety, especially when walking to her car at the end of a shift. These were, as Donnelly puts it, clearly 'physical threats' (Francis, 2013a, p. 236) that implied that she may be attacked, leading to a member of her family having to come to collect her at night as she was too afraid to walk to her car in the dark on her own. This implied to Donnelly that she was marked out, stigmatized for reprisal and possible attack.

On one occasion, a Staff Nurse followed Donnelly into the toilet/locker room and, locking the door behind her, demanded to know 'if I was going to say anything about her, and basically threatening me not to do so' (Francis, 2013a, p. 236). As a consequence of these actions and threats, Donnelly finally felt that the atmosphere at the hospital had become so 'poisonous' (Francis, 2013a, p. 111) that she decided she had no option but to leave the Trust.

In the case of Julie Bailey, the woman whose mother had died in the Trust's care, a vicious, hateful response from Trust staff members, and those associated with them, ensued. It started off in indirect ways with, according to Bailey, some of the staff on the ward taking away the chair on which she used to sleep when she stayed overnight while looking after her mother, following which 'they would be slower and 
slower bringing Mum's drugs around, she would be waiting six hours for a heart pill' (Adams, 2013).

It got more explicit when Bailey started receiving extensive, anonymous hate mail. Subsequently, she had her car tyres slashed, had the word 'Bitch' and 'Shut your effing mouth' written on her windows, and received cards with messages such as 'I hope you die in an ambulance on the way to hospital' (Adams, 2013). These stigmatizing practices left Bailey in no doubt that she was hated and was effectively being told she was a marked woman.

The stigmatizing also included the vandalizing of Bailey's mother's grave on a regular basis, and her receiving a card taunting her with the question: 'Isn't it about time you started looking after your mum's grave? Ha ha ha ...' (Adams, 2013). In due course Bailey stopped going out on her own in Stafford town because '[w]hen I did ... people would come up in my face and shout: 'Nobody died at the hospital. You are making it all up"' (Adams, 2013). While it is not possible to know the exact identities of those who enacted this, there can be little doubt that it involved employees of the Trust and those acting on behalf of them. Finally, fearful for her own safety, Bailey left Stafford, 'effectively being run out of town' (Adams, 2013).

The consequences for these whistleblowers included feelings of loneliness and isolation, with Donnelly reporting that 'it felt almost like a conspiracy. I felt completely on my own' (Francis, 2013a, p. 109), and Bailey feeling that she had been so ostracized by those associated with the hospital that her position in the community had been effectively destroyed. Another consequence was a deep sense of anxiety, with Donnelly fearing for her safety at the end of the shift, and ultimately coming to the conclusion that she had no option but to leave the employment of the Trust. Similarly, Bailey felt that she was at risk living in Stafford: initially she reported that 
her anxiety was such that 'I don't go out here on my own any more' (Adams, 2013), but as life got worse she was effectively forced to leave the town, fearing for own her safety.

\section{Understanding the Mid Staffordshire Case}

I now turn to develop an understanding of the Mid Staffordshire case, using the Kleinian psychoanalytic theoretical framework outlined earlier. It is clear that the whistleblowers at Mid Staffordshire were experienced as a major problem and were hated by some of the Trust staff, but the key question, as has been noted, is why this should be the case. I would argue that the significance of nurse Donnelly, Julie Bailey and other whistleblowers was not only that they were experienced as 'others' who represented opposing viewpoints to those of the staff, an argument that is wellestablished in the whistleblower literature. Instead, they may also be understood to have represented the part of the Trust's staff - a good part of the 'self' they had lost that was emblematic of the truth, as well as standing for integrity, honesty and dedication to the work and the welfare of patients. This is best understood using Klein's (1975) concepts of splitting and projective identification, whereby a part here, the good part - of the self is unconsciously split off and lodged in others, in this case the whistleblowers.

This problem had, first, to do with the function of facing and telling the truth, one that the staff, and especially the nurses, had effectively lost. Whether staff willingly falsified documents, or felt that they were forced to do so; and whether they callously neglected facing the truth about the terrible conditions the patients faced, or felt badly about this neglect; there could have been little doubt that, consciously or unconsciously, they must have been aware that they were not facing up to the truth of the situation, or allowing it to come to light. The issue of truth telling was central to 
Helene Donnelly's insistence that, as a nurse, she should not be forced to fabricate data and lie about waiting times. Telling the whole truth was also central to Julie Bailey's activities that included displaying on the walls of her café the photographs of many of the patients who had died unnecessarily at the Trust, so that no one who died in this way would be forgotten. Having lost their capacity to face and tell the truth, I argue, staff members felt that the whistleblowers such as Helene Donnelly and Julie Bailey reminded them of this shortcoming, and this was felt to be very disturbing.

Second, the difficulty with Helene Donnelly and Julie Bailey was that they unconsciously represented the function of doing effective work in caring for patients, one that was no longer available to these staff, and this therefore made these two individuals highly problematic for those staff. Within the context of the shocking revelations that have emerged from this case, it is perhaps easy to forget that the Trust was staffed by people, many of whom, at least at some level, aspired to help those who were unwell. As expressed by one of the doctors who had most vociferously expressed his concerns about poor standards at the Trust, Clinical Lead for Emergency Medicine Dr Chris Turner, '[w]here care was less than it should have been, this was never through a desire to provide that level of care...I saw numerous examples of selfless devotion on the part of staff...all done to provide the best quality of care that they were able to' (Francis, 2013a, p. 179). It would be reasonable to assume that there is truth in this assertion, that the Trust was not devoid of good work, or at least the desire to do good work, and that the values and aspirations of the staff and what motivated them to work in this sector - were closely connected with ideas of helping people and saving lives. I argue that, given the magnitude of the problems they encountered on a daily basis, these staff are likely to have felt that they had 
largely lost this function, and nurse Donnelly and Julie Bailey were unconsciously experienced, in a somewhat provocative way, to represent the function they had lost.

This issue of doing the work of the organization was highly troublesome in relation to Helene Donnelly, who was unrelenting in her focus on the care provided for patients in Accident and Emergency. It was also particularly problematic in relation to Julie Bailey, who was not employed by the Trust, but who moved into the ward to care for her mother, much to the chagrin of the staff on the ward. Bailey claimed to be doing the work that the staff should have done, and publicly stated that, as well as providing the essential care for her mother, she had cared for and prolonged the lives of several others on the ward. Bailey, I would argue, was thus felt to have challenged the integrity of staff members by - at least from their point of view being felt to have 'invaded' the organization, intruding on the work of the staff and usurping their roles.

I argue that this situation was felt by staff members to be intolerable because, not only did the very existence of these whistleblowers signify the truth, as well as the desire to do the work of looking after the patients, but their complaints gave these staff members a glimpse of the disaster that they themselves had colluded with. As Bion (1967, p. 86) has argued, powerful projective identification may be highly problematic because it enables a momentary and distressing sight of the disaster that is being denied, and recognition of this must then be avoided at all costs.

This disturbing reality was felt to be so uncomfortable and distressing that these staff felt forced to turn on the whistleblowers, effectively blaming the messenger. As Waddell (1998, p. 127) puts it, the recipients of such projective identification are blamed for the sins of those who are doing the projecting, and these recipients must therefore be attacked and punished for this. The problem was then felt 
to be located entirely with Donnelly and Bailey (as well as the other whistleblowers), so that much energy needed to be expended to damage, stigmatize and exclude them.

In summary, I argue that the hatred and stigmatization directed towards Donnelly and Bailey were intensified by unconscious projections of the lost good parts of the self of others in the service, and that staff hated these whistleblowers because they unconsciously stood for what the staff couldn't do, but would like to have done. This led almost inexorably to highly irrational attacks on the whistleblowers, who were thus hated not exclusively because they were 'others' who had stood in opposition to the staff group, but because they unconsciously represented the functions of the staff group themselves that they had lost. Particularly irksome for staff was that these whistleblowers had given them sight of the disastrous state of the organization, and this was felt to be intolerable, leading to the hatred and stigmatization directed towards the whistleblowers.

In asserting the above, I argue that the strength of the idea of the lost good self lies in it being a plausible and helpful explanation for the hatred and animosity - and the resulting retaliation and stigmatization - that are directed against the whistleblower. While there is no dispute with the existing, well-established and important view that the whistleblower represents the 'other' who opposes the organization, the argument of this paper is that the experience of the whistleblower as the oppositional 'other' occurs largely at a conscious level, and that the intensity of the hatred and stigmatization suggests that there is more at play here. The argument of this paper is that, especially where staff members have an ethical commitment to the work, as well as representing the oppositional other, the whistleblower also unconsciously represents the very part of the self of the colleague that has been lost, a self that is linked with the whistleblower's concern with moral and ethical values 
(Avakian \& Roberts, 2012), truth (Alford, 2001), as well as their commitment to organizational and professional norms and values (Kenny, Fotaki \& Vanderkerckhove, 2018).

In exploring the data for this hypothesis, it is important to note that this argument does not depend on articulated statements of staff members that reveal that the whistleblowers represented their lost selves: as these thoughts are unconscious, it is not possible for staff members to give explicit voice to them, and so we should not expect to find direct evidence of this kind. In other words, given that projective identification involves unconscious processes, staff members would not have had conscious thoughts that the whistleblower was emblematic of their lost good selves, and would therefore not have articulated these ideas in this way: at a conscious level, they simply hated the whistleblowers for betraying them. This view of the relationship between data and hypotheses is consistent with a wider body of psychoanalytic inquiry that involves a 'highly inductive process' (Vidaillet \& Gamot, 2015, p. 996) and includes the making of 'plausible interpretations' (Vince \& Mazen, 2014, p. 197), where such an approach is essential in order to access 'the more subtle, less obvious aspects of human functioning' (Stein, 2016, p. 922) that are the focus of this kind of investigation.

\section{Discussion}

This paper makes contributions to two areas of literature, one of which is the literature on whistleblowers. A first element of the contribution to this area of literature is (a) is to offer a new explanation for the hatred and stigmatization directed towards whistleblowers, especially in those cases where staff members have made deep moral commitments to working on the task of the organization. Rather than viewing whistleblowers as being hated and stigmatized exclusively because they 
represent the 'other' who stands in opposition to staff members and the organization, I take a different view and argue that, as well as representing the 'other', whistleblowers may unconsciously also represent the lost good part of the 'self' of the staff member.

I go on to argue that this lost aspect is problematic for staff members because it is indicative of the capacity to face the truth as well as do the work of the organization, and thus signifies a deep sense in which the organization and its staff members - who have lost much of these functions - have failed. As this also compels the staff member to glimpse the serious or even catastrophic problems they have been trying to avoid, it inclines them to turn on the whistleblower, effectively blaming the messenger. Framing the hatred and stigmatization in this way is important because it helps us understand the function of these processes: blaming the whistleblower obviates the need for feelings of guilt or concern within the staff members themselves, and enables them to psychologically extricate themselves from their sense of responsibility for what has occurred.

I also inform the literature on whistleblowers by (b) developing ideas that have implications for the power and politics framing that shapes much of the writing in this area. While various authors have made important contributions in fleshing out the power aspects of whistleblower retaliation, the argument of this paper suggests an alternative focus, that the struggle is not only among or between social actors, but within them, so that the struggle is not only between people but within the minds of people.

This paper thus suggests that when whistleblowers are subject to 'ostracism by coworkers' (Rothschild \& Miethe, 1999, p. 120) or stigmatization and retaliation by 'top management ... supervisor or coworkers' (Mesmer-Magnus \& Viswesvaran, 
2005, p. 281), the political framing is helpfully supplemented by a quite different view: whistleblowers, according to this paper, are hated not only because they are the 'other' who stands up in opposition, but because they unconsciously represent the good 'self' that staff members have lost and no longer have access to. Whistleblowers are thus 'derealized subjects' (Kenny, 2018, p. 1031) not only because of interpersonal and political dynamics, but because of intra-personal dynamics within the minds of the staff members themselves.

By supplementing extant power and politics explanations with the one offered in this paper, we are thus able to deepen our understanding of the hatred directed towards whistleblowers because - representing the loss of the good self that staff members find too painful to bear - the very existence of such whistleblowers unconsciously alludes to the failure of the staff group, and this is felt to be intolerable. Such an explanation therefore suggests a deepening of the power and politics focus because it implies that, as well as being in conflict with whistleblowers, staff members are unconsciously at war with themselves, and that their hatred and animosity have as much to do with 'internal' conflicts as with 'external' ones. This reflects the psychoanalytic ideas of authors such as Canham (2002) who argues that members of a group may become endemically engaged in a power struggle or war against others that is fuelled by unconscious projective identification at both interand intra-personal levels, and that this struggle may incline them to become 'gripped by an idée fixe' (Canham, 2002, p. 119) or obsession that their survival is dependent on the destruction of those others.

A second area of literature that this paper contributes to is that which applies psychoanalytic ideas to the study of management and organization. One element of this is (a) a contribution to the Kleinian understanding of splitting and projective 
identification: while Petriglieri and Stein note that the splitting of the self into good and bad elements may lead to 'either unpalatable aspects of the self or, conversely, desired aspects of the self' (2012, p. 1222) being projected into others, thus far only the former - the projection of the bad aspects - has been explored in this literature. Vince and Mazen focus on 'projecting the violent aspects of one's own unconscious onto the other' (2014, p. 192); Horwitz describes the process of people projecting their 'bad, corrosive qualities' (1985, p. 23) into others; Stein writes of aspects of the self being 'unconsciously felt by the individual to be problematic ... [so that] ... the individual may split them off and project into someone else' (1998, p. 558); while especially focusing on the projection of immoral, corrupt or dishonest aspects of the self - Petriglieri and Stein describe the 'unconscious projection of unwanted aspects of one's self into others' (2012, p. 1217).

This paper therefore adds to this literature by exploring a quite different variant of projective identification, that individuals may project good parts of themselves, such as their capacity to face the truth or care for other people. The hatred they bear towards others, that draws on the 'mute and hidden' (Rosenfeld, 1987, p. 107) forces of the death instinct, may occur precisely because these others unconsciously remind them of the good aspects that they have lost, and are unable to retrieve. Extending our understanding of these defensive activities is important not only because it increases and nuances our understanding of such projective processes, but because it provides substance for the counter-intuitive idea that the projection of good aspects may also be profoundly problematic: where projective processes are involved, you can hate others not only because they unconsciously represent bad parts of yourself, but because they represent good parts that you have lost, and your antipathy towards them lies in their reminding you of this loss. 
I also contribute to the literature that applies psychoanalysis to the study of management and organizations by (b) deepening the debates between the Kleinian and Lacanian perspectives. The Lacanian approach suggests that, as the subject has 'no essence' (Vidaillet \& Gamot, 2015, p. 991), any ideas that we may harbour about being autonomous, self-authoring and in control are invariably constructed 'in an illusory fashion' (Driver, 2010, p. 566). As a consequence, '[a]ny sense of interiority [of the self] can be nothing but imaginary' (Harding, 2007, p. 1763), and a true understanding can only be achieved by 'accepting that the self is, by nature, split, incomplete and struggling' (Kenny, 2012, p. 1177). The ideas of this paper link with these themes because they suggest that a key way in which the integrity of the self may be undermined is by splitting and projective identification, so that the illusion of the autonomous self may lie in part in the unconscious lodging of good aspects of the self in the other. This lends support to Fotaki's proposal to 'purposefully integrate Lacanian and Kleinian insights' (2010, p. 714) by drawing out the affinities and points of contact between these two approaches.

The ideas of this paper also suggest a number of areas for future research, one of which concerns our understanding of organizations that have had adversarial relationships with outside agencies such as regulators, tax authorities, or the police. The research questions provoked by this paper concern whether such conflictual relationships may be associated with similar unconscious experiences of shame in organizational members as those explored in the whistleblower case, as well as the resulting hatred and stigmatization directed against those experienced as being the source of the shame, here the outside agencies. The ideas of this paper thus suggest that if such external agencies exert their authority in relation to an organization by enforcing the law and enacting penalties for those who disobey, the hatred and 
stigmatization that organizational members are likely to direct towards them may be exacerbated by these agencies or their staff being unconsciously emblematic of the lost good self of these members. The research focus of studies in these areas could include whether any resulting hatred and stigmatization bears the same hallmarks as those found in the present paper, or whether they are different, and, if so, in what ways.

Finally, by contributing to the literatures on whistleblowing and the application of psychoanalysis to the study of management and organization, as well as pointing the way to areas of further research and exploration, this paper explores new territory. In doing so, I hope to have contributed to thinking by deepening our understanding in these areas.

\section{References}

Adams, T. (2013). Mid Staffs whistleblower Julie Bailey: 'I don’t go out here on my own any more', The Guardian, 27 October.

Alford, C. F. (2001). Whistleblowers: Broken lives and organizational power. Ithaca: Cornell University Press.

Arnaud, G. (2012). The contribution of psychoanalysis to organization studies and management: An overview. Organization Studies, 33(9), 1121-1135.

Ash, A. (2016). Whistleblowing and ethics in health and social care. London: Jessica Kingsley.

Ashforth, B.E. (2019). Stigma and legitimacy: Two ends of a single continuum or different continua altogether? Journal of Management Inquiry, 28(1), 22-30. 
Avakian, S., \& Roberts, J. (2012). Whistleblowers in organizations: Prophets at work? Journal of Business Ethics, 110(1), 71-84.

Baker, D.T., \& Kelan, E.K. (2019). Splitting and blaming: The psychic life of neoliberal executive women. Human Relations, 72(1), 69-97.

Bion, W.R. (1967). On arrogance. In W.R. Bion (Ed.), Second thoughts: Selected papers on psychoanalysis (pp. 86-92). London: Maresfield.

Bolsin, S. N. (2003). Whistle blowing. Medical Education, 37(4), 294-296.

Braddock, L. (2011). Psychological identification, imagination and psychoanalysis. Philosophical Psychology, 24(5), 639-657.

Brown, A.D. (2004). Authoritative sensemaking in a public inquiry report. Organization Studies, 25(1), 95-112.

Brown, A.D., \& Jones, M. (2000). Honourable members and dishonourable deeds: Sensemaking, impression management and legitimation in the 'Arms to Iraq Affair'. Human Relations, 53(5), 655-689.

Campbell, D. (2011). Neglect and indignity: Stafford hospital inquiry damns NHS failings, The Guardian, 1 December.

Canham, H. (2002). Group and gang states of mind. Journal of Child Psychotherapy, 28(2), 113-127.

Contu, A. (2014). Rationality and relationality in the process of whistleblowing: Recasting whistleblowing through readings of Antigone. Journal of Management Inquiry, 23(4), 393-406. 
Cresswell, J.W. (1994). Research design: Qualitative and quantitative approaches. Thousand Oaks, CA: Sage.

Currie, G., Richmond, J., Faulconbridge, J., Gabbioneta, C., \& Muzio, D. (2019). Professional misconduct in healthcare: Setting out a research agenda for work sociology. Work, Employment and Society, 33(1), 149-161.

Devers, C.E., Dewett, T., Mishina, Y., \& Belsito, C.A. (2009). A general theory of organizational stigma. Organization Science, 20(1), 154-171.

Driver, M. (2010). Learning as lack: Individual learning in organizations as an empowering encounter with failed imaginary constructions of the self. Management Learning, 41(5), 561-574.

Elliston, F. A. (1982). Anonymity and whistleblowing. Journal of Business Ethics, 1(3), 167-177.

Francis, A. (2013a). Report of the Mid Staffordshire NHS Foundation Trust Public Inquiry. Volume 1. Analysis of evidence and lessons learnt (Part 1). Retrieved from:

https://assets.publishing.service.gov.uk/government/uploads/system/uploads/at tachment_data/file/279115/0898_i.pdf

Francis, A. (2013b). Report of the Mid Staffordshire NHS Foundation Trust Public Inquiry. Volume 2. Analysis of evidence and lessons learnt (Part 2). Retrieved from:

https://assets.publishing.service.gov.uk/government/uploads/system/uploads/at tachment_data/file/279118/0898_ii.pdf 
Francis, A. (2013c). Report of the Mid Staffordshire NHS Foundation Trust Public Inquiry. Volume 3. Present and future; Annexes. Retrieved from: https://assets.publishing.service.gov.uk/government/uploads/system/uploads/at tachment_data/file/279121/0898_iii.pdf

Francis, A. (2013d). Report of the Mid Staffordshire NHS Foundation Trust Public Inquiry. Volume 4. Executive summary. Retrieved from: https://assets.publishing.service.gov.uk/government/uploads/system/uploads/at tachment_data/file/279124/0947.pdf

Fotaki, M. (2006). Choice is yours: A psychodynamic exploration of health policymaking and its consequences for the English National Health Service. Human Relations, 59(12), 1711-1744.

Fotaki, M. (2010). Why do public policies fail so often? Exploring health policymaking as an imaginary and symbolic construction. Organization, 17(6), 703720.

Fotaki, M., \& Hyde, P. (2015). Organizational blind spots: Splitting, blame and idealization in the National Health Service. Human Relations, 68(3), 441-462.

Fotaki, M., Long, S., \& Schwartz, H.S. (2012). What can psychoanalysis offer organization studies today? Taking stock of current developments and thinking about future directions. Organization Studies, 33(9), 1105-1120.

Gephart, R.P. (1993). The textual approach: Risk and blame in disaster sensemaking. Academy of Management Journal, 36(6), 1465-1514. 
Gilmore. T.N., \& Krantz, J. (1985). Projective identification in the consulting relationship: Exploring the unconscious dimensions of a client system. Human Relations, 38(12), 1159-1177.

Glazer, M. P., \& Glazer, P. M. (1989). The whistle-blowers: Exposing corruption in government and industry. New York: Basic Books.

Goffman, E. (1990). Stigma: Notes on the management of spoiled identity. London: Penguin Books.

Harding, N. (2007). On Lacan and the 'Becoming-ness' of Organizations/Selves. Organization Studies, 28(11), 1761-1773.

Helms, W.S., Patterson, K.D.W., \& Hudson, B.A. (2019). Let's not “taint” stigma research with legitimacy, please. Journal of Management Inquiry, 28(1), 5-10.

Horwitz, L. (1985). Projective identification in dyads and groups. In A. D. Coleman, \& M.H. Geller (Eds.), Group Relations Reader 2 (pp. 21-35). Washington D.C.: A. K. Rice Institute.

James, G. (1993). Back from the edge; Promotion and vindication for the officer who stood alone. The New York Times, 30 October.

Jubb, P. B. (1999). Whistleblowing: A restrictive definition and interpretation. Journal of Business Ethics, 21(1), 77-94.

Kenny, K. (2012). 'Someone big and important': Identification and affect in an international development organization. Organization Studies, 33(9), 11751193.

Kenny, K. (2018). Censored: Whistleblowers and impossible speech. Organization Studies, 71(8), 1025-1048. 
Kenny, K., Fotaki, M., \& Scriver, S. (2018). Mental health as a weapon: Whistleblower retaliation and normative violence. Journal of Business Ethics. Published online ahead of print at: https://link.springer.com/article/10.1007/s10551-018-3868-4

Kenny, K., Fotaki, M., \& Vanderkerckhove, W. (2018). Whistleblower subjectivities: Organization and passionate attachment. Organization Studies. Published online ahead of print at: https://journals.sagepub.com/doi/full/10.1177/0170840618814558

Klein, M. (1975). Notes on some schizoid mechanisms. In M. Klein (Ed.) Envy and gratitude and other works (1946-1963) (pp. 1-24). London: The Hogarth Press.

Lennane, J. (2012). What happens to whistleblowers, and why. Social Medicine, 6(4), 249-258.

Lovell, A., \& Robertson, C. (1994.) Charles Robertson: In the eye of the storm. In G. Vinten (Ed.), Whistleblowing: Subversion or corporate citizenship? (pp. 146173). London: Paul Chapman Publishing.

Mansbach, A. (2007). Political surplus of whistleblowing: A case study. Business Ethics: A European Review, 16(2), 124-131

Mason, A. (2012). Vicissitudes of projective identification. In: E. Spillius, \& E. O'Shaughnessy (Eds.), Projective Identification: The Fate of a Concept (pp. 301-320). London: Routledge.

Mesmer-Magnus, J.R., \& Viswesvaran, C. (2005). Whistleblowing in organizations: An examination of correlates of whistleblowing intentions, actions and retaliation. Journal of Business Ethics, 62(3), 277-297. 
Miceli, M.P., \& Near, J.P. (1994). Whistleblowing: Reaping the benefits. Academy of Management Executive, 8(3), 65-72.

Miller, E.J. (1993). From dependency to autonomy: Studies in organization and change. London: Free Association Books.

Moore, P., \& Haworth, M. (2015). Crash, bank, wallop: The memoirs of the HBOS whistleblower. London: New Wilberforce Media.

Munro, I. (2017). Whistle-blowing and the politics of truth: Mobilizing 'truth games' in the Wikileaks case. Human Relations, 70(5), 519-543.

Near, J.P., Dworkin, T.M., \& Miceli, M.P. (1993). Explaining the whistle-blowing process: Suggestions from power theory and justice theory. Organization Science, 4(3), 393-411.

Near, J.P., \& Miceli, M.P. (1985). Organizational dissidence: The case of whistleblowing. Journal of Business Ethics, 4(1), 1-16.

Near, J. P., \& Miceli, M. P. (1995). Effective whistleblowing. Academy of Management Review, 20(3), 679-708.

Near, J. P., \& Miceli, M. P. (1996). Whistle-blowing: Myth and reality. Journal of Management, 22(3), 507-526.

National Health Executive (2013). Stafford hospital nurses lied to meet A\&E targets, inquiry hears. 5 March. Retrieved from:

http://www.nationalhealthexecutive.com/News/stafford-hospital-nurses-liedto-meet-ae-targets-inquiry-hears/45296 
Paetzold, R. L., Dipboye, R. L., \& Elsbach, K. D. (2008). A new look stigmatization in and of organizations. Academy of Management Review, 33(1), 186-193.

Parmerlee, M. A., Near, J. P., \& Jensen, T. C. (1982). Correlates of whistleblowers' perceptions of organizational reprisals. Administrative Science Quarterly, 27(1), 17-34.

Pentland, B.T. (1999). Building process theory with narrative: From description to explanation. Academy of Management Review, 24(4), 711-724.

Perry, N. (1998). Indecent exposures: Theorizing whistleblowing. Organization Studies, 19(2), 235-257.

Petriglieri, G., \& Stein, M. (2012). The unwanted self: Projective identification in leaders' identity work. Organization Studies, 33(9), 1217-1235.

Rehg, M, T., Miceli, M. P., Near, J. P., \& Van Scotter, J. R. (2008). Antecedents and outcomes of retaliation against whistleblowers: Gender differences and power relationships. Organization Science, 19(2), 221-240.

Rosenfeld, H.A. (1987). Impasse and interpretation: Therapeutic and anti-therapeutic factors in the psychoanalytic treatment of psychotic, borderline and neurotic patients. London: Tavistock and the Institute of Psychoanalysis.

Rothschild, J., \& Miethe, T.D. (1999). Whistle-blower disclosures and management retaliation: The battle to control information about organization corruption. Work and Occupations, 26(1), 107-128.

Sawer, P. (2009). Staffordshire hospital scandal: The hidden story, The Telegraph, 22 March. 
Spillius, E. (2012). Developments by British Kleinian analysts. In: E. Spillius, \& E. O'Shaughnessy (Eds.), Projective Identification: The Fate of a Concept (pp. 4960). London: Routledge.

Stein, M. (1998). Projective identification in management education. Journal of Managerial Psychology, 13(8): 558-566.

Stein, M. (2016). 'Fantasy of fusion' as a response to trauma: European leaders and the origins of the eurozone crisis. Organization Studies, 37(7), 919-937.

Uys, T. (2000). The politicization of whistleblowers: A case study. Business Ethics: A European Review, 9(4), 259-267.

Vandekerckhove, W., \& Tsahuridu, E.E. (2010). Risky rescues and the duty to blow the whistle. Journal of Business Ethics, 97(3), 365-380.

Vidaillet, B., \& Gamot, G. (2015). Working and resisting when one's workplace is under threat of being shut down: A Lacanian perspective. Organization Studies, 36(8), 987-1011.

Vince, R., \& Mazen, A. (2014). Violent innocence: A contradiction at the heart of leadership. Organization Studies, 35(2), 189-207.

Vinten, G. (1994). Whistleblowing - fact and fiction. An introductory discussion. In G. Vinten (Ed.), Whistleblowing: Subversion or corporate citizenship? (pp. 320). London: Paul Chapman Publishing.

Waddell, M. (1998). The scapegoat. In R. Anderson, \& A. Dartington (Eds.), Facing it out: Clinical perspectives on adolescent disturbance (pp. 127-141). London: Duckworth. 
Weiskopf, R., \& Tobias-Miersch, Y. (2016). Whistleblowing, parrhesia and the contestation of truth in the workplace. Organization Studies, 37(11), 16211640.

Wiesenfeld, B.M., Wurthmann, K.A., \& Hambrick, D.C. (2008). The stigmatization and devaluation of elites associated with corporate failures: A process model. Academy of Management Review, 33(1), 231-251. 